mouse was obtained for gene expression analyses by qPCR. Splenic tissue was harvested from each mouse for gene expression analyses by qPCR, as well as pooled collectively for each group for immunophenotyping through flow cytometry. The latter was also done for superficial inguinal and draining popliteal lymph node (LN) tissue. Statistical analysis was done using the unpaired student's t-test with $\mathrm{p}<0.05$ considered significant.

Results Preliminary findings showed no significant difference in clinical phenotype of $\mathrm{K} / \mathrm{BxN}$ serum-induced arthritis between $\mathrm{KO}$ and control mice. Gene expression profiling of whole joint tissue showed decreases in TNF $\alpha$, IL-6, IFN- $\gamma$ expression, as well as selective Notch target gene expression, while maintaining comparable IL-1, CXCL10, and IL-12p40 levels. Surprisingly, expression levels of FoxP3 in $\mathrm{KO}$ mice versus controls were significantly decreased in both joint and splenic tissue $(p=0.0244$ and $p=0.0286$, respectively). Immunophenotyping of splenic and LN tissue showed increased proportions of CD4 $+\mathrm{T}$ cells in $\mathrm{KO}$ mice versus controls, but a markedly lower proportion of CD4+CD25+FoxP3+ cells. Lower proportions of $\mathrm{F} 4 / 80+$ and Ly6G + cell populations in splenic and draining $\mathrm{LN}$ tissue of $\mathrm{KO}$ mice versus controls, but higher populations of Ly6C + cells, were also observed.

Conclusions Deletion of RBP-J in the myeloid compartment does not lead to phenotypic differences in $\mathrm{K} / \mathrm{BxN}$ serum-induced inflammatory arthritis, though selective modulation of pro-inflammatory cytokine gene expression in vivo does occur. Decreased gene expression of FoxP3 and fewer CD4+CD25+FoxP3 + cells in RBP-J deleted mice may contribute to this selective modulation. The functional significance of these findings, coupled with differences in myeloid cell composition and trafficking observed, remain undetermined and will be further studied.

\section{A3.26 IDENTIFYING T-FOLLICULAR-HELPER-LIKE CELL INVOLVEMENT IN THE ORGANIZATION OF TUBULOINTERSTITIAL INFLAMMATION IN HUMAN LUPUS NEPHRITIS AND RENAL ALLOGRAFT REJECTION}

doi:10.1136/annrheumdis-2013-203216.26

'V Liarski, 'D Brandt, ' $\mathrm{N}$ Kaverina, ${ }^{1} \mathrm{~S}$ Henderson, ${ }^{2} \mathrm{~A}$ Chang, ${ }^{1} \mathrm{~T}$ Utset, ${ }^{3} \mathrm{C}$ Labno, ${ }^{4} \mathrm{Y}$ Peng, ${ }^{4} Y$ Jiang, ${ }^{4} \mathrm{M}$ Giger, ${ }^{1} \mathrm{M}$ Clark. ${ }^{1}$ Section of Rheumatology, Department of Medicine and Knapp Center for Lupus Research, University of Chicago, Chicago, IL 60637; '2Department of Pathology, University of Chicago, Chicago, IL 60637; 'Integrated Microscopy Core Facility and Knapp Center for Biomedical Discovery, University of Chicago, Chicago, IL 60637; ${ }^{4}$ Department of Radiology, University of Chicago, Chicago, IL 60637

Background Tubulointerstitial inflammation (TII) is a usual feature of lupus nephritis (LuN) and the infiltrate is organised into well-circumscribed T:B-cell aggregates or germinal centre-like structures.

Materials and Methods We analysed $42 \mathrm{LuN}$ biopsies using confocal laser scanning microscopy (CLSM) for the qualitative presence of $\mathrm{T}_{\mathrm{FH}}$-like $\mathrm{CD}^{+} \mathrm{ICOS}^{+}$cells $\left(\mathrm{T}_{\mathrm{IH}}\right)(\mathrm{n}=19$ for ICOS-positive cases $)$ and compared this with T-cell-mediated (TCM, $\mathrm{n}=8)$ and mixed renal allograft (mixed RT, $n=7$ ) rejection cases. Cellular make-up and relationships within TII were examined using CLSM to identify and compare the locations of $\mathrm{T}_{\mathrm{IH}}$ cells and $\mathrm{CD} 20^{+} \mathrm{B}$ cells by means of a computerised cell-distance algorithm.

Results The prevalence of $\mathrm{T}_{\mathrm{IH}}$ cells was found to be $45.2 \%$ in $\mathrm{LuN}$, $64.2 \%$ in TCM, and 50\% in mixed RT cases. Presence of these cells in LuN was statistically correlated with a worse grade of TII as scored by a blinded pathologist (2.05 versus $1.48, \mathrm{p}=0.04)$. ICOSpositive biopsies were associated with a higher mean serum creatinine in adult patients at time of biopsy $(2.3$ versus $1.1 \mathrm{mg} / \mathrm{dL}$, $\mathrm{p}=0.03$ ) as well as GFR as measured by the MDRD equation and adjusted for patient sex (44.8 versus $74.1 \mathrm{~mL} / \mathrm{min} / 1.73 \mathrm{~m}^{2}, \mathrm{p}=0.04$ ) with no statistical differences in age, sex, ISN/RPS LuN class, or $\mathrm{NIH}$ activity or chronicity indices.
Cellular distance mapping revealed that $\mathrm{T}_{\mathrm{IH}}$ cells were spatially related to $\mathrm{CD}_{20}{ }^{+} \mathrm{B}$ cells across $\mathrm{LuN}$ (42.9\% of cells within 0.27 microns, $\mathrm{n}=10$ biopsies), control tonsil tissue $(65.3 \%, \mathrm{n}=2$ biopsies), and mixed RT cases (70.3\%, $\mathrm{n}=7$ biopsies) as compared to other $\mathrm{T}$ cells (less than $20 \%$ for all groups, respectively). These associations remained unchanged after correction for total cellular density and T:B cell ratios. Low-density TCM cases showed a comparatively low rate of $\mathrm{T}_{\mathrm{IH}}$ : $\mathrm{B}$ cell association $(15.0 \%, \mathrm{n}=8$ biopsies) and these results were statistically significant $(p<0.0001$ versus mixed RT and tonsil cases, $p=0.002$ versus LuN). Comparing the above results against a theoretical model of random $\mathrm{T}_{\mathrm{IH}}$ : $\mathrm{B}$-cell distribution revealed that the likelihood of our observations in $\mathrm{LuN}$ being due to chance was approximately $8.12 \times 10^{-41}$

Conclusions Our data reveal that $\mathrm{T}_{I H}$ cells are present in similar rates across cases of renal allograft rejection as well as LuN. Their presence is associated with a higher degree of TII as well as worse renal function at time of biopsy in LuN. $\mathrm{T}_{\mathrm{IH}}$ cells are more likely to form proximal conjugates with naïve and activated $B$ cells in tissues of diseases associated with aberrant autoantibody production (SLE, mixed RT) but not in processes where autoantibodies are absent (TCM).

\section{Metabolism, hormones and autoimmunity}

\section{A4.1 1.25(OH $)_{2} \mathrm{D}_{3}$ MODULATES GENE EXPRESSION INVOLVED IN PHENOTYPE STABILITY AND MIGRATION OF TH17 CELLS FROM PATIENTS WITH RHEUMATOID ARTHRITIS}

doi:10.1136/annrheumdis-2013-203217.1

1,2W Dankers, 1,2JP van Hamburg, 1,2PS Asmawidjaja, 1,2N Davelaar, 1,2SMJ Paulissen, 1,2K Wen, 1,2AMC Mus, 'EM Colin, 3JPTM van Leeuwen, 'JMW Hazes, 1,2E Lubberts. ${ }^{1}$ Departments of Rheumatology; ${ }^{2}$ Immunology and ${ }^{3}$ Internal Medicine, Erasmus MC, University Medical Center Rotterdam, The Netherlands

Background and Objectives Vitamin D has suppressive effects on autoimmune diseases, such as rheumatoid arthritis (RA). Within these diseases, T-helper-17 (Th17) cells have been implicated to play a crucial role in the development and progression of chronic inflammation. Recently, we have found that the active vitamin $\mathrm{D}$ compound, $1.25(\mathrm{OH})_{2} \mathrm{D}_{3}$, has direct suppressive effects on both human and mouse Th17 cytokine expression and activity. Using gene-expression profiling, we aim to identify molecular targets of $1.25(\mathrm{OH})_{2} \mathrm{D}_{3}$ signalling underlying this suppressive action of $1.25(\mathrm{OH})_{2} \mathrm{D}_{3}$ in Th17 cells.

Methods Primary Th17 cells were sorted from peripheral blood of treatment naïve patients with early RA and cultured with or without $1.25(\mathrm{OH})_{2} \mathrm{D}_{3}$. From these cultures gene-expression profiles were generated. Expression of genes of interest was confirmed by Q-PCR and/or specific ELISA.

Results In the presence of $1.25(\mathrm{OH})_{2} \mathrm{D}_{3}$, protein expression of Th17 associated cytokines IL-17A and IL-22 was inhibited, while in contrast the anti-inflammatory cytokine IL-10 was induced. These findings were supported by the gene-expression profiles from these cultures. Furthermore, $1.25(\mathrm{OH})_{2} \mathrm{D}_{3}$ inhibited transcription of the cytokine receptors IL-23R and IL-7R, which are involved in Th17 survival and proliferation. Chemokines CCL20 and CXCL10 were down-regulated and chemokine receptors CCR2, CXCR6, CXCR3 and CCR10 were up-regulated. Importantly, ROR $\gamma t$, which is critically involved in Th17 differentiation and function and the cell-size regulator and oncogene c-Myc were down-regulated by $1.25(\mathrm{OH})_{2} \mathrm{D}_{3}$

Conclusions: From these findings, we concluded that $1.25(\mathrm{OH})_{2} \mathrm{D}_{3}$ modulates the expression of genes involved in cytokine production, proliferation, and migration of Th17 cells. These data indicate that $1.25(\mathrm{OH})_{2} \mathrm{D}_{3}$ not only suppresses Th17 cell activity but also regulates Th17 phenotype stability and migration of these cells to sites of tissue inflammation in RA. 